\title{
Mesenchymal Stem Cell-conditioned Medium Alleviates High Fat-induced Hyperglucagonemia via miR-181a-5p and its Target PTEN/AKT Signaling
}

\section{Jia Song}

Shandong University Qilu Hospital

Qin He

Shandong University Qilu Hospital

\section{Xinghong Guo}

Shandong University Qilu Hospital

\section{Lingshu Wang}

Shandong University Qilu Hospital

Jinbang Wang

Shandong University Qilu Hospital

Chen Cui

Shandong University Qilu Hospital

Huiqing $\mathrm{Hu}$

Shandong University Qilu Hospital

\section{Mengmeng Yang}

Shandong University Qilu Hospital

Yixin Cui

Shandong University Qilu Hospital

\section{Fei Yan}

Shandong University Qilu Hospital

Jun Qin

Shandong University Qilu Hospital

\section{Zheng Sun}

Shandong University Qilu Hospital

\section{Xinguo Hou}

Shandong University Qilu Hospital

\section{Wenjuan Li}

Shandong University Qilu Hospital

Li Chen ( $\square$ chenli3@medmail.com.cn )

Shandong University Qilu Hospital 
Research

Keywords: a-cells, bmMSC-CM, glucagon secretion, miR-181a-5p, PTEN/AKT

Posted Date: October 28th, 2020

DOI: https://doi.org/10.21203/rs.3.rs-96610/v1

License: (c) (i) This work is licensed under a Creative Commons Attribution 4.0 International License. Read Full License

Version of Record: A version of this preprint was published at Molecular and Cellular Endocrinology on November 1st, 2021. See the published version at https://doi.org/10.1016/j.mce.2021.111445. 


\section{Abstract}

Background: Pancreatic a-cells are critical to glucose homeostasis because they release glucagon and stimulate the liver to produce glucose. Dysregulation of a-cells gives rise to fasting and postprandial hyperglycemia in type 2 diabetes mellitus(T2DM). Mesenchymal stem cells (MSCs) or their conditioned medium can improve islet function and enhance insulin sensitivity in target tissues. However, studies showing the direct effect of MSCs on islet a-cell dysfunction are limited.

Methods: In this study, we used high-fat diet (HFD)-induced mice and a-cell line exposure to palmitate (PA) to determine the effects of bone marrow-derived MSC-conditioned medium (bmMSC-CM) involved in glucagon secretion. To investigate the potential signaling pathways, phosphatase and tensin homolog deleted on chromosome 10 (PTEN) , AKT and phosphorylated AKT(p-AKT) were assessed by Western blotting.

Results: In vivo, bmMSC-CM infusion protected against HFD-induced hyperglycemia and hyperglucagonemia. Consistently, bmMSC-CM decreased PA-induced glucagon secretion in a-cells and isolated islets. Additionally, bmMSC-CM reduced intracellular PTEN expression and rescued AKT signaling. Previous studies and the TargetScan database indicate that miR-181a and its target PTEN play vital roles in ameliorating a-cell dysfunction. We observed that miR-181a-5p is highly expressed in BMMSCs but prominently lower in aTC1-6 cells. Overexpression or downregulation of miR-181a-5p respectively alleviates or aggravates glucagon secretion in aTC1-6 cells via the PTEN/AKT signaling pathway.

Conclusions: Our observations suggest that MSC-secreted miR-181a-5p mitigates glucagon secretion of a-cells by regulating PTEN/AKT signaling. These findings might provide a novel understanding of MSCbased treatment.

\section{Introduction}

Pronounced changes in lifestyle and environment have made type 2 diabetes mellitus (T2DM) a global health issue. Among adults in China, the estimated overall prevalence of diabetes is $10.9 \%$, and that for prediabetes is $35.7 \%$ [1]. T2DM is characterized by dysfunction of pancreatic $\beta$-cells and insulin resistance. Nevertheless, a-cells cannot be underestimated because their function to release glucagon and stimulate the liver to produce glucose [2]. Dysregulation of a-cells results in fasting and postprandial hyperglycemia in T2DM [3] and is accompanied by a higher glucagon-to-insulin ratio and augmentation of the pancreatic $a$ - to $\beta$-cell area ratio $[4,5]$. In addition, there is also increased glucagon concentrations in prediabetes [6]. Fasting glucagon concentrations are associated with a longitudinal decline of $\beta$-cell function in non-diabetics [7].

Free fatty acids increase glucagon secretion in a-cell lines and isolated islets [8-12], among which a-cells exposed to fatty acids show insulin resistance of the IRS-1/PI3K/Akt pathway that likely controls glucagon secretion [12]. Phosphatase and tensin homolog deleted on chromosome 10 (PTEN) is a potent 
negative regulator of the PI3K/AKT pathway. Its deletion in pancreatic a-cells alleviates high-fat diet (HFD)-induced hyperglucagonemia and insulin resistance [13].

Several recent clinical trials have indicated that mesenchymal stromal cell (MSC)-based therapies are effective in decreasing blood glucose and alleviating some complications such as diabetic foot injuries and diabetic retinopathy [14-18]. MSCs or their conditioned medium not only ameliorate pancreatic $\beta$-cell injury $[19,20]$ and islet endothelium apoptosis and functional impairment [21], but also enhance the sensitivity of insulin target tissues [22-24]. However, studies showing the direct effect of MSCs on pancreatic a-cell dysfunction are limited. An increasing number of studies indicate that the rationale for MSC therapy is based on its paracrine action rather than its differentiation mechanism [25-27]. Based on these reports, we hypothesize that MSCs could improve the function of pancreatic a-cells by secreting various factors.

Therefore, in this study, we used HFD-induced mice and a-cell line exposure to PA to investigate the effects and mechanisms of bone marrow-derived MSCs conditioned medium (bmMSC-CM) in relation to glucagon secretion.

\section{Materials And Methods}

\section{Culture of rat bone marrow mesenchymal stem cells (BM- MSCs)}

Rat primary bone marrow MSCs (BM-MSCs) were obtained by isolating the femurs of rats and flushing the marrow. Then, they were cultured in Dulbecco's modified Eagle's medium/Nutrient Mixture F-12 (DMEM/F12) (Gibco, USA) with $20 \%$ fetal bovine serum (FBS; Gibco) supplemented with $100 \mathrm{U} / \mathrm{mL}$ penicillin and $100 \mu \mathrm{g} / \mathrm{mL}$ streptomycin (Gibco). The culture medium was changed every 2 days until the cells reached $80-90 \%$ confluency. After the first passage, the MSCs were cultured in DMEM/F12 with 10\% FBS. Cultures were maintained at $37^{\circ} \mathrm{C}$ in a humidified atmosphere of $5 \% \mathrm{CO}_{2}$ in air.

\section{Identification and differentiation of BM-MSCs and preparation of MSC-conditioned medium}

Flow cytometry analysis was performed to identify MSCs according to characteristics that they are positive for CD90 and CD44 (BD, USA) and negative for CD34 (BD), and CD45 (Santa Cruz Biotechnology, USA). The BM-MSCs were analyzed for their ability to differentiate into adipocytes and osteoblasts by Oil Red O (Sigma-Aldrich, USA) staining of lipid droplets and Alizarin Red S staining (Sigma-Aldrich) of calcium nodes. Once the MSCs reached $80-90 \%$ confluency, the medium was replaced with serum-free medium and harvested for $24 \mathrm{~h}$. Subsequently, the supernatant was collected and concentrated 20 times using 10-kDa MW cutoff ultrafiltration membranes (Ultra-15 10K; Millipore). Finally, the bmMSC-CM was sterilized by filtration through a $0.22-\mu \mathrm{m}$ filter and stored at $-80^{\circ} \mathrm{C}$.

\section{Animal models and bmMSC-CM administration}


Six-week-old male C57BL/6J mice were purchased from the Model Animal Research Center of Shandong University (Jinan, China) (Ethical number: DWLL-2019-016). The mice were housed with a 12-h light/dark cycle at a temperature $\left(22-25^{\circ} \mathrm{C}\right)$ - and humidity $(55 \pm 5 \%)$-controlled environment. After one-week of adaptive feeding, the mice were randomly divided into the NCD group (which were fed a normal chow diet) and the HFD group (which were fed a $45 \%$ high-fat diet, purchased from Botai Hongda Biotechnology Co., Ltd, Beijing, China). After nine months of HFD, we seperated them into two groups: HFD + PBS and HFD + bmMSC-CM. Approximately $200 \mu \mathrm{L}$ of the bmMSC-CM concentrate, which is equivalent to a total of $100 \mu \mathrm{g}$ of bmMSC-CM protein per mouse, were injected into the mice via their tail vein every 3 days for 10 cycles.

\section{Animal procedures}

The intraperitoneal glucose tolerance test (IPGTT) was performed after bmMSC-CM administration. Each group contained four mice selected via randomization procedure. Tail vein blood glucose levels were measured by Accu-Chek ${ }^{\circledR}$ Performa (Roche Life Science, USA) at 0, 15, 30, 60, 90, 120, and 150 min after i.p. injection of $2 \mathrm{~g} / \mathrm{kg}$ body weight of glucose. The area under the curve (AUC) was calculated using the trapezoidal rule. After the mice were anaesthetized, their pancreas were fixed in $4 \%$ paraformaldehyde for immunofluorescence staining for structural assessment of islets. The sera of mice were stored at $-80^{\circ} \mathrm{C}$ for glucagon enzyme-linked immunosorbent assay (ELISA; Bluegene, Shanghai, China).

\section{Immunofluorescence staining of the pancreas}

The pancreas that were fixed in $4 \%$ paraformaldehyde were embedded in paraffin, sectioned at $5-\mu \mathrm{m}$ thickness, and mounted on glass slides. The slides were dewaxed, and then antigen retrieval was performed using antigen unmasking buffer. After blocking for $30 \mathrm{~min}$ at room temperature in a proteinblocking solution ( $10 \%$ normal goat serum), the slides were incubated with anti-mouse insulin antibody (Proteintech, China, Cat: 66198-1-Ig, 1:1,000) and anti-rabbit glucagon antibody (Proteintech, Cat:15954-1AP, 1:200) overnight at $4{ }^{\circ} \mathrm{C}$. The slides were then incubated with goat anti-rabbit FITC (Zhongshan, Beijing, China, Cat: ZF-0311, 1:200) and goat anti-mouse TRITC(Zhongshan, Cat: ZF-0313, 1:200) for $60 \mathrm{~min}$ at room temperature and then stained for DAPI for $5 \mathrm{~min}$. Fluorescence was observed and captured using a fluorescence microscope (Olympus BX53, Japan). The areas of the islets, a cells, and $\beta$ cells were analyzed by Image Pro Plus software. The $\alpha$-or $\beta$-cell ratio in islets was measured by the glucagon or insulin-positive area divided by both-positive area ( $n=3$ mice and 45 islets).

\section{a-Cell culture and processing}

Palmitate (PA; Sigma-Aldrich, USA) was prepared by dissolving and heating equimolar amounts of $\mathrm{NaOH}$ and palmitate in distilled water to a concentration of $500 \mathrm{mmol} /$ liter palmitate. This was further diluted with $5 \%$ bovine serum albumin (BSA) (fatty acid free; Sigma) to make a stock solution of $50 \mathrm{mmol} /$ liter palmitate. The stock solution was filter-sterilized and stored at $-20^{\circ} \mathrm{C}$, and palmitate solution was freshly prepared before each experiment. 
aTC1-6 cells were obtained from the American Type Culture Collection (ATCC Number: CRL-2934 ${ }^{\mathrm{TM}}$ ) and cultured in DMEM/high-glucose medium (Gibco, USA) supplemented with $10 \% \mathrm{FBS}, 100 \mathrm{U} / \mathrm{mL}$ penicillin, and $100 \mu \mathrm{g} / \mathrm{mL}$ streptomycin at $37^{\circ} \mathrm{C}$, in a $5 \% \mathrm{CO}_{2}$ incubator. InR1G9 cells were cultured in Roswell Park Memorial Institute (RPMI)-1640 medium (Gibco, USA) with 10\% FBS and antibiotics. Both a cells were cultured to $70-80 \%$ confluency before treatment. In detail, a cells were randomly divided into the following three groups: normal control group, PA treatment group (PA, $0.5 \mathrm{mM})$, and rescue group with addition of bmMSC-CM (PA + bmMSC-CM).

\section{Isolation and purification of islets from mice}

Islets were isolated from normal C57BL/6J mice by collagenase $\mathrm{V}(1.5 \mathrm{mg} / \mathrm{mL}$, Cat. no. C8170; Solarbio) and DNase $\otimes(62.5 \mathrm{U} / \mathrm{mL}$, Cat. no. EN0521; Thermo Fisher) digestion followed by hand picking under a stereoscopic microscope (Olympus SZX7). Briefly, we sacrificed the mice and separated the pancreas followed by washing with ice-cold Hanks solution. Then, the pancreas were incubated in $1 \mathrm{~mL}$ Hanks

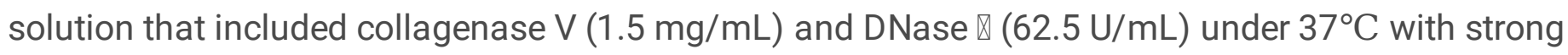
oscillation for about $12 \mathrm{~min}$, until it was disintegrated into a fine sand-like suspension. Subsequently, we added $5 \mathrm{~mL}$ of ice-cold Hanks with $10 \%$ FBS to stop the digestion, mixed them, and then kept them on ice. After three minutes of natural settlement, we discarded the supernatant and washed the sediment with ice-cold Hanks solution thrice. To purify the isolated islets, we picked the islets into DMEM under a stereoscopic microscope. After incubation overnight, the islets were exposed to $1 \mathrm{mM}$ PA and bmMSC-CM for $48 \mathrm{~h}$ and used to glucagon secretion assay.

\section{Glucagon secretion}

After stimulation with PA and bmMSC-CM, both of a-cells and isolated islets were incubated for $2 \mathrm{~h}$ in Krebs-Ringer buffer (KRB) containing $2.5 \mathrm{mmol} / \mathrm{L}$ glucose. Supernatants were collected and kept at $80^{\circ} \mathrm{C}$ for glucagon ELISA.

\section{Preparation of cell lysate and western blot analysis}

After washing with ice-cold PBS, the cells were lysed in radioimmunoprecipitation assay (RIPA) lysis buffer (P0013B, Beyotime, Shanghai, China) for approximately $30 \mathrm{~min}$. Then, the samples were centrifuged at $12,000 \mathrm{rpm}$ at $4{ }^{\circ} \mathrm{C}$ for $15 \mathrm{~min}$. Protein concentration was determined using the bicinchoninic acid (BCA) method (Beyotime, China). Subsequently, proteins were separated by $10 \%$ sodium dodecyl sulfate-polyacrylamide gel electrophoresis (SDS-PAGE) (EpiZyme, China) and transferred onto polyvinylidene difluoride (PVDF) membranes (IPVH00010 $0.45 \mu \mathrm{m}$, Millipore, USA). Then, the membranes were blocked with 5\% skim milk in Tris-buffered saline solution containing Tween-20 (SigmaAldrich, USA) for $1 \mathrm{~h}$ at room temperature and incubated in specific primary antibodies at $4{ }^{\circ} \mathrm{C}$ overnight. After detection by horseradish peroxidase-conjugated secondary antibodies for $1 \mathrm{~h}$ at room temperature, the proteins were visualized using enhanced chemiluminescence.

The primary antibodies were as follows: PTEN (Abcam, USA, Cat. no. ab32199, 1:10000), Phosphor-AKT (CST, USA, Cat. no. 4060S, 1:2000), AKT (Abcam, Cat. no. ab179463, 1:10000), GADPH (Boster, China, 
Cat. no. BA2913, 1:500).

\section{Real-time quantitative PCR analysis}

Total RNA from BM-MSCs and aTC1-6 cells was extracted using an E.Z.N.A. MicroElute Total RNA Kit (Cat. no. R6831-01; Omega BioTek, USA) following the manufacturer's instructions. Next, $1 \mu \mathrm{g}$ RNA was reverse-transcribed into cDNA using a Prime Script RT Reagent Kit (Cat. no. RR047A; Takara, Japan). Primers were chemically synthesized by GenePharma (Shanghai, China) Co., Ltd. The primer sequences were as follows: rno-mir-181a-5p, sense 5'-ATTCTCTCAAACATTCAACGCTG-3' and antisense 5'TATGGTTGTTCTGCTCTCTGTGTC-3'; U6, sense 5'-CAGCACATATACTAAAATTGGAACG-3' and antisense 5'ACGAATTTGCGTGTCATCC-3'. Real-time PCR was conducted with the SYBR Green PCR kit (Cat. no. RR420A; Takara), gene expression changes were determined with the comparative $C T$ (2- $\Delta \Delta C t)$ method, and quantification was achieved by normalization using $\mathrm{U} 6$ as control.

\section{Luciferase reporter assay}

Luciferase reporter assay was conducted as previously described [28]. Wild-type PTEN 3' UTR firefly luciferase reporter plasmids or PTEN 3' UTR firefly luciferase reporter plasmids with the potential miR$181 a-5 p$ binding site mutated were co-transfected with miR-181a-5p mimics or miR-NC mimics into aTC16 cells using Lipofectamine 2000 (Invitrogen), respectively. After $48 \mathrm{~h}$ of transfection, the luciferase assay was performed using a Dual-Glo Luciferase Assay Kit (Promega, Cat: E2920) according to the manufacturer's protocol.

\section{Cell transfection}

To study the effect of miR-181a-5p secreted by BM-MSCs and its target PTEN on glucagon secretion of a cells, we altered their expression by transfecting miR-181a-5p mimics and a negative control (NC), inhibitors and an miRNA inhibitor negative control (inhibitor NC), small interfering RNA (siRNA) for PTEN and its NC into aTC1-6 cells, respectively. All oligonucleotides were synthesized by Shanghai GenePharma Co., Ltd. Their sequences were as follows: rno-miR-181a-5p mimics, sense 5'AACAUUCAACGCUGUCGGUGAGU-3' and antisense 5'-UCACCGACAGCGUUGAAUGUUUU-3'; NC, sense 5'UUCUCCGAACGUGUCACGUTT-3' and antisense 5'-ACGUGACACGUUCGGAGAATT-3'; rno-miR-181a-5p inhibitors 5'-ACUCACCGACAGCGUUGAAUGUU-3'; inhibitor NC 5'-CAGUACUUUUGUGUAGUACAA-3'; siRNAPTEN, sense 5'-CCCACCACAGCUAGAACUUTT-3' and antisense 5'-AAGUUCUAGCUGUGGUGGGTT-3'; and siRNA-NC, sense 5'-UUCUCCGAACGUGUCACGUTT-3' and antisense 5'-ACGUGACACGUUCGGAGAATT-3'.

aTC1-6 cells were transfected with miR-181a-5p oligomer and siRNA for PTEN using Lipofectamine 2000 transfection reagent (Invitrogen, USA) according to the manufacturer's instructions. Briefly, the aTC1-6 cells were plated in 6-well plates until they reached $80-90 \%$ confluency. The medium was then removed and replaced by Opti-MEM I Reduced Serum Medium (Gibco) mixed with miR-181a-5p mimics (12.5 nM), inhibitor $(150 \mathrm{nM})$, or siRNA for PTEN $(125 \mathrm{nM})$ for $6 \mathrm{~h}$. Subsequently, the culture medium was replaced by RPMI-1640 medium with 10\% FBS, and the cells were treated with PA or bmMSC-CM. After $48 \mathrm{~h}$, the cells and supernatant were collected for the next experiments. RT-qPCR analysis was performed to assess 
transfection efficiency, whereas ELISA and western blot analysis were used for the detection of supernatant glucagon and PTEN/AKT signaling pathway, respectively.

\section{Statistical analysis}

Differences between two groups were evaluated using the $t$ test; for three groups or more, a one-way ANOVA was performed. Differences between the values were considered to be significant at $P<0.05$. All of the statistical analyses were carried out with GraphPad Prism 5, and all of the graphs were also created with this software.

\section{Results}

\section{Identification of BM-MSCs}

The bone marrow-derived MSCs (BM-MSCs) were identified by their specific surface markers, and osteogenic and adipogenic differentiation. Fluorescence-activated cell sorter (FACS) analysis showed that MSCs were positive for stem cell markers CD90 and CD44 and negative for hematopoietic markers CD34 and CD45 (Fig. 1a). After culturing in adipogenic medium for 14 days, cells differentiated toward adipocytes, which were identified by Oil Red 0 stain for lipid droplets (Fig. 1b). Likewise, osteogenic differentiation of MSCs was apparent after 21 days, which was determined by Alizarin Red S staining for calcium precipitation (Fig. 1C).

\section{bmMSC-CM infusion ameliorates HFD-induced hyperglycemia and hyperglucagonemia in mice}

To evaluate the effects of bmMSC-CM on pancreatic a-cells in vivo, we administered bmMSC-CM into HFD-fed mice. We found that bmMSC-CM infusion significantly reduced fasting glucose levels and improved the glucose tolerance during IPGTT. The AUC also supported the above findings (Fig. 2a). Circulating glucagon levels of HFD mice were higher than NCD mice, whereas bmMSC-CM infusion mitigated HFD-induced hyperglucagonemia (Fig. 2b). In addition, bmMSC-CM infusion ameliorated HFDinduced hypertrophy of islets (Figs. $2 c$ and $2 d$ ) and decreased $\alpha$ and $\beta$ cell area (Figs. $2 e$ and $2 f$ ) while there was no change in the $\alpha$ - and $\beta$-cell ratio (Figs. $2 \mathrm{~g}$ and $2 \mathrm{~h}$ ).

\section{bmMSC-CM regulated palmitate-induced hypersecretion of glucagon and PTEN/AKT signaling in a-cells and isolated islets}

To observe the effect of MSCs on pancreatic a-cells in vitro, we used bmMSC-CM to culture aTC1- 6 cells, InR1G9 cells, and isolated islets of mice that were preexposed to PA. ELISA and western blotting were performed for the detection of glucagon levels in supernatants and intracellular PTEN/AKT signaling, respectively. We found that in both a-cells and isolated islets, glucagon levels in supernatants were higher in PA-preexposed cells than in the control (Figs. 3a, 3c, 3e). PA promoted the expression of PTEN and 
repressed the phosphorylation of AKT (Ser473) (Figs. 3b, 3d, 3f). However, bmMSC-CM remarkably reduced PA-induced glucagon secretion (Figs. 3a, 3c, 3e). Meanwhile, in the bmMSC-CM treatment group, intracellular PTEN expression decreased, and phosphorylation of AKT(Ser473) was rescued (Figs. 3b, 3d, $3 \mathrm{f})$. All of these phenomena indicated that bmMSC-CM was able to alleviate hypersecretion of glucagon and PTEN/AKT signaling transduction of a-cells.

\section{PTEN deletion suppresses PA-induced glucagon secretion in a-cells}

To determine the direct effects of PTEN on glucagon secretion in a-cells, we performed siRNA PTEN knockdown experiments using aTC1-6 cells. siRNA PTEN transfection led to efficient reduction in PTEN protein expression with increased p-Akt (Fig. 4a). Meanwhile, PA-induced glucagon secretion was attenuated after PTEN knockdown (Fig. 4b). These results suggest that PTEN/AKT signaling is involved in regulating glucagon secretion in a-cells.

\section{Verification of miRNA secreted by BM-MSCs and its target gene}

MicroRNAs (miRNAs) are important factors secreted by MSCs. To investigate the specific mechanism by which BM-MSCs regulate PTEN, we focused on miRNAs. miRNAs are small (19-24 nt) and highly conserved non-coding RNA molecules that regulate gene expression at the post-transcriptional level and play critical roles in regulating differentiation, paracrine action, and other cellular activities[29].

Studies have shown that MSCs secrete high amounts of miR-181 [30, 31]. The miR-181 family serves as a metabolic rheostat in vivo through the nonredundant regulation of PTEN [32]. Therefore, we first compared the differential expression of miR-181a-5p between BM-MSCs and aTC1-6 cells by RT-qPCR. We found that the mRNA level of miR-181a-5p in BM-MSCs was apparently higher than aTC1- 6 cells (Fig. 5a). Furthermore, the expression of miR-181a-5p in aTC1-6 cells increased after treatment with bmMSC-CM (Fig. 5b), which indicated that miR-181a-5p secreted by BM-MSCs gain entry into aTC1-6 cells.

MiRNAs exert their functions by interacting with the $3^{\prime}$ untranslated region (3' UTR) or protein coding sequence of target mRNAs [33]. Therefore, to further confirm that PTEN is the target gene of miR-181a-5p, we performed sequence analysis and dual-luciferase reporter assay combined with TargetScan database. Sequence analysis revealed there is a conserved miR-181a-5p binding site in the $3^{\prime}$ UTR of PTEN mRNA (Fig. 5c), PTEN was identified as a candidate target gene of miR-181a-5p consequently, and it is associated with glucagon secretion of a-cells [13]. To explore whether miR-181a-5p directly targets PTEN, a luciferase reporter plasmid containing the predicted miRNA-binding site of PTEN(pGL3-PTEN ${ }^{\text {WT- }}{ }^{\prime} \mathrm{UTR}^{-}$) was generated. We co-transfected with pGL3-PTEN ${ }^{W T-3}{ }^{\prime} U T R$ reporter plasmids and miR-181a-5p mimics or miR-NC into aTC1-6 cells, and the results showed that overexpression of miR-181a-5p inhibited the luciferase activity of PTEN 3'-UTR reporter genes. However, this inhibition was abolished when two key 


\section{MSC-secreted miR-181a-5p is involved in regulating glucagon secretion and PTEN/AKT signaling in a-cells}

To further corroborate the role of miR-181a-5p, aTC1-6 cells were transfected with miR-181a-5p mimics or inhibitor followed by exposure to PA or bmMSC-CM. The expression of miR-181a-5p significantly increased with the application of mimics (Fig. 6a) and reduced by inhibitor (Fig. 6d). There was a decrease in PA-induced glucagon secretion (Fig. 6b), accompanied by reduction of PTEN expression and recovery of p-AKT (Fig. 6c) after transfection with miR-181a-5p mimics. In contrast, miR-181a-5p inhibitor transfection resulted in enhanced glucagon secretion (Fig. 6e), upregulated expression of PTEN, and a decrease in p-AKT signaling (Fig. 6f). Additionally, bmMSC-CM partially rescued this process. Consequently, miR-181a-5p secreted by BM-MSCs is involved in regulating glucagon secretion and PTEN/AKT signaling of a cells.

\section{Discussion}

In this study, we investigated the possible mechanisms by which bmMSC-CM alleviates the high fatinduced a-cell dysfunction. By secreting miR-181a-5p, MSCs downregulated the expression of PTEN, a negative regulator of the PI3K/AKT pathway, and subsequently restored the phosphorylation of AKT and prevented hypersecretion of glucagon in a-cells.

Pancreatic a-cells are located in the islets of Langerhans, which constitute an important endocrine part of the pancreas. In mouse islets, approximately $10-30 \%$ of cells are a-cells, and even up to $65 \%$ of them in human islets [34, 35]. In 1948, Sutherland and Dove established that a-cells could release glucagon [36]. The main role of glucagon is to increase the release of glucose from the liver during fasting and exercise. Therefore, pancreatic a-cells play an important part in glucose homeostasis. However, in both diabetes and prediabetes, glucagon secretion is dysregulated, thereby further exaggerating hyperglycemia [3, 6 , 37]. Previous in vitro studies showed that fatty acids stimulate glucagon secretion in isolated mouse islets and aTC1 cells, and the chain length, spatial configuration, and degree of unsaturation of fatty acids influence the glucagonotropic effect $[12,38]$.

Previous studies have suggested that systemic infusion of MSCs could improve islet function and ameliorate hyperglycemia $[19,20,39]$. However, studies illustrating the effect of MSCs on islet a-cells are limited. In our study, we found that bmMSC-CM infusion alleviates HFD-induced hyperglycemia and hyperglucagonemia in vivo. Meanwhile, hypertrophy of islets was mitigated and there was decrease in islet area, $\alpha$ - and $\beta$-cell area compared with HFD mice, whereas no change in $\alpha$ - and $\beta$-cell ratio was 
detected. In vitro, bmMSC-CM treatment decreased PA-induced glucagon secretion in aTC1-6 cells, InR1G9 cells, and isolated islets.

Glucagon secretion by a-cells is under glucose and paracrine hormone control, in which the classical intracellular PI3K/AKT signaling pathway play a major role. Hyperglycemia increases a-cell proliferation and glucagon contents through PI3K/p-AKT changes and subsequent FoxO1 modulation [40]. Insulin from neighboring $\beta$ cells directly inhibit glucagon secretion [41]. a-cells exposed to PA show impaired transduction of PI3K/AKT pathway and insulin resistance, which likely controls glucagon secretion [12]. As a potent negative regulator of PI3K/AKT pathway, upregulation of PTEN activity and transcription by PA mediate its inhibitory effects on insulin signaling [42]. PTEN deletion in $\beta$-cells improve glucose intolerance and $\beta$-cell function in HFD-fed or $\mathrm{db} / \mathrm{db}$ mice [43]. PTEN deletion in a-cells protect against high-fat diet-induced hyperglucagonemia and insulin resistance [13]. In vitro, we found that PA promotes the expression of PTEN and inhibits phosphorylation of AKT in a-cells. Nevertheless, bmMSC-CM downregulates PA-induced PTEN expression and rescues AKT signaling.

Several studies have proposed that MSCs exert functions through modulation of autophagy [20], suppressing inflammation [23, 24], or secreting important factors such as Wnts[21]. Recently, an increasing number of studies related to MSC therapy have focus on its paracrine action[25-27]. MiRNAs are small (19-24 nt) and highly conserved non-coding RNA molecules that repress gene expression by directly binding to the 3' UTR of target messenger RNAs (mRNAs) [44]. Microarray analysis shows that miR-181 displayed abundant expression in MSC-EXO. The miR-181 family consists of six mature miRNAs, namely, miR-181a-1, miR-181a-2, miR-181b-1, miR-181b-2, miR-181c, and miR-181d, which are encoded by three independent paralog precursor transcripts on three different chromosomes [31]. Our RT-qPCR results suggest that there is prominently higher abundance of miR-181a-5p in BM-MSCs than aTC1-6 cells and that bmMSC-CM increases miR-181a-5p levels in aTC1-6 cells.

miR-181 abundance is lower in the placenta from women with pregestational overweight/obesity or gestational obesity [45]. The deregulation of miR-181 alters hepatic insulin sensitivity [46]. Henao-Mejia et al. [32] found that miR-181-deficient mice displayed robust phenotypes associated with impaired metabolic fitness, and miR-181-deficient cells displayed suboptimal glucose uptake and reduced glycolytic rates. The absence of miR-181 leads to increased PTEN activity, inhibition of the PI3K pathway activity, and therefore AKT activation. The miR-181 family acts as a metabolic rheostat in vivo through the nonredundant regulation of PTEN. Through overexpression and lower expression of miR-181a-5p in aTC1-6 cells, we verified its role in the regulation of PTEN/AKT signaling and secretion of glucagon. Thus, we propose that MSCs secrete miR-181a-5p, which targets PTEN/AKT signaling to alleviate the hypersecretion of glucagon in a-cells.

\section{Conclusions}

In summary, our results indicate that MSC-secreted miR-181a-5p could mitigate glucagon secretion of acells by regulating PTEN/AKT signaling. This is first study that shows that bmMSC-CM could alleviate 
high fat-induced hyperglucagonemia in pancreatic a-cells. These findings might provide a novel understanding of MSC-based treatments.

\section{Abbreviations}

MSCs:mesenchymal stem cells; BM-MSCs:bone marrow mesenchymal stem cells; bmMSC-CM:bone marrow-derived MSC-conditioned medium; T2DM:type 2 diabetes mellitus; NCD:normal chow diet; HFD:high-fat diet; PA:palmitate; PTEN:phosphatase and tensin homolog deleted on chromosome 10; $p$ AKT:phosphorylated AKT; DMEM/F12:Dulbecco's modified Eagle's medium/Nutrient Mixture F-12; FBS:fetal bovine serum; IPGTT:intraperitoneal glucose tolerance test; AUC:area under the curve; ELISA:enzyme-linked immunosorbent assay; BSA:bovine serum albumin; KRB:Krebs-Ringer buffer; RIPA:radioimmunoprecipitation assay; BCA:bicinchoninic acid; NC:negative control; siRNA:small interfering RNA; miRNAs:microRNAs; 3' UTR:3' untranslated region

\section{Declarations}

\section{Acknowledgments}

We thank LetPub (www.letpub.com) for its linguistic assistance during the preparation of this manuscript.

\section{Authors' contributions}

JS performed the experiments, collected data, performed data analysis, and wrote the manuscript. QH, XHG, LSW and JBW helped perform the experiments. CC, HQH, MMY and YXC helped with the sample collection. FY, JQ, ZS and XGH provided technical support and guided the data analysis. WJL and LC supervised the overall study design. All authors read and approved the final version of the manuscript.

\section{Funding}

This work was supported by the National Natural Science Foundation of China (grant numbers 81670706, 81873632, 81770818, 81800727, 81500591, 81800736), the National Key Research and Development Program of China (grant numbers 2016YFC0901204, 2018YFC1311800), the Taishan Scholars Foundation of Shandong Province (ts201712089), and the Natural Science Foundation of Shandong Province (ZR2019BH018).

\section{Availability of data and materials}

All data generated or analysed during this study are included in this published article 


\section{Ethics approval and consent to participate}

All animal-related experiments, including the isolation of rat BM-MSCs, the HFD-induced mice modeling, the bmMSC-CM infusion, and the isolation of mice islets, were conducted in accordance with the Animal Ethics Committee of Shandong University(Ethics Number:DWLL-2019-016).

\section{Competing interests}

All authors declare that they have no competing interests.

\section{Consent for publication}

All authors gave consent for publication.

\section{Author details}

${ }^{1}$ Department of Endocrinology, Qilu Hospital of Shandong University, No.107 Wenhua Xi Road, Jinan 250012, Shandong, China. ${ }^{2}$ Institute of Endocrine and Metabolic Diseases of Shandong University, Jinan 250012, Shandong, China. ${ }^{3}$ Key Laboratory of Endocrine and Metabolic Diseases, Shandong Province Medicine \& Health, Jinan 250012, Shandong, China.

\section{References}

1. Wang L, Gao P, Zhang M, Huang Z, Zhang D, Deng Q, Li Y, Zhao Z, Qin X, Jin D, Zhou M, Tang X, Hu Y and Wang L. Prevalence and Ethnic Pattern of Diabetes and Prediabetes in China in 2013. JAMA.2017; 317:2515-2523.

2. Baetens $D$, Malaisse-Lagae F, Perrelet A, Orci L. Endocrine pancreas:three-dimensional reconstruction showstwotypes of islets of langerhans. Science.1979; 206:1323-1325

3. Dunning BE, Gerich JE. The role of alpha-cell dysregulation in fasting and postprandial hyperglycemia in type 2 diabetes and therapeutic implications. Endocrine reviews. 2007; 28:253-83.

4. Fujita Y, Kozawa J, Iwahashi H, Yoneda S, Uno S, Eguchi H, Nagano H, Imagawa A and Shimomura I. Human pancreatic alpha- to beta-cell area ratio increases after type 2 diabetes onset. $J$ Diabetes Investig.2018; 9:1270-1282.

5. Lee M, Kim M, Park JS, Lee S, You J, Ahn CW, Kim KR and Kang S. Higher glucagon-to-insulin ratio is associated with elevated glycated hemoglobin levels in type 2 diabetes patients. Korean $\mathrm{J}$ Intern Med. 2019;34(5):1068-1077.

6. Sharma A, Varghese RT, Shah M, et al. Impaired Insulin Action Is Associated With Increased Glucagon Concentrations in Nondiabetic Humans. J Clin Endocrinol Metab.2018;103(1): 314-319. 
7. Adams JD, Dalla Man C, Laurenti MC, et al. Fasting glucagon concentrations are associated with longitudinal decline of $\beta$-cell function in non-diabetic humans. 2020; 8;105:154175.

8. Hong J, Jeppesen PB, Nordentoft I, Hermansen K. Fatty acidinduced effect on glucagon secretion is mediated via fatty acid oxidation. Diabetes Metab Res Rev.2007; 23:202-210.

9. Bollheimer LC, Landauer HC, Troll S, Schweimer J, Wrede CE, Scho“Imerich J, Buettner R. Stimulatory short-term effects of free fatty acids on glucagon secretion at low to normal glucose concentrations. Metabolism.2004; 53:1443-1448.

10. Olofsson CS, Salehi A, Go"pel SO, Holm C, Rorsman P. Palmitate stimulation of glucagon secretion in mouse pancreatic a-cells results from activation of L-type calcium channels and elevation of cytoplasmic calcium. Diabetes.2004; 53:2836-2843

11. Collins SC, Salehi A, Eliasson L, Olofsson CS, Rorsman P. Long-term exposure of mouse pancreatic islets to oleate or palmitate results in reduced glucose-induced somatostatin and oversecretion of glucagon. Diabetologia.2008; 51:1689-1693

12. Piro S, Maniscalchi ET, Monello A, Pandini G, Mascali LG, Rabuazzo AM and Purrello F. Palmitate affects insulin receptor phosphorylation and intracellular insulin signal in a pancreatic alpha-cell line. Endocrinology. 2010;151:4197-206.

13. Wang L, Luk CT, Cai EP, Schroer SA, Allister EM, Shi SY, Wheeler MB, Gaisano HY, Woo M. PTEN Deletion in Pancreatic a-Cells Protects Against High-Fat Diet-Induced Hyperglucagonemia and Insulin Resistance. Diabetes. 2015;64:147-157.

14. Wehbe T, Chahine NA, Sissi S, Abou-Joaude I and Chalhoub L. Bone marrow derived stem cell therapy for type 2 diabetes mellitus. Stem Cell Investig.2016;3:87.

15. Bhansali S, Dutta P, Kumar V, Yadav MK, Jain A, Mudaliar S, Bhansali S, Sharma RR, Jha V, Marwaha N, Khandelwal N, Srinivasan A, Sachdeva N, Hawkins M, Bhansali A. Efficacy of Autologous Bone Marrow-Derived Mesenchymal Stem Cell and Mononuclear Cell Transplantation in Type 2 Diabetes Mellitus: A Randomized, Placebo-Controlled Comparative Study. Stem cells and development.2017;26:471-81.

16. Li M, Zhao Y, Hao H, Dong L, Liu J, Han W, Fu X. Umbilical cord-derived mesenchymal stromal cellconditioned medium exerts in vitro antiaging effects in human fibroblasts. Cytotherapy.2017;19:37183.

17. Dong M, Zhang W, Chen S, Wang JM, Duan HT, Kong JH,Wang YX, Bi X, Song J. The protective effect of human umbilical cord mesenchymal stem cells-induced neural stem cells in the vitreous on the blood-retinal barrier in diabetic rats. [Zhonghua yan ke za zhi] Chinese journal of ophthalmology. 2017;53:53-8.

18. Cil N, Oguz EO, Mete E, Cetinkaya A and Mete GA. Effects of umbilical cord blood stem cells on healing factors for diabetic foot injuries. Biotech Histochem. 2017;92:15-28.

19. Liu C, Zhang W, Peradze N, Lang L, Straetener J, Feilen PJ, Alt M, Jager C, Laubner K, Perakakis N, Seufert $\mathrm{J}$ and Path $\mathrm{G}$. Mesenchymal stem cell (MSC)-mediated survival of insulin producing 
pancreatic beta-cells during cellular stress involves signalling via Akt and ERK1/2. Mol Cell Endocrinol.2018;473:235-244.

20. Zhao K, Hao H, Liu J, Tong C, Cheng Y, Xie Z, Zang L, Mu Y and Han W. Bone marrow-derived mesenchymal stem cells ameliorate chronic high glucose-induced beta-cell injury through modulation of autophagy. Cell Death Dis. 2015; 6:e1885.

21. Wang L, Qing L, Liu H, Liu N, Qiao J, Cui C, He T, Zhao R, Liu F, Yan F, Wang C, Liang K, Guo X, Shen $\mathrm{YH}$, Hou $\mathrm{X}$ and Chen L. Mesenchymal stromal cells ameliorate oxidative stress-induced islet endothelium apoptosis and functional impairment via Wnt4-beta-catenin signaling. Stem Cell Res Ther.2017;8:188.

22. Si Y, Zhao Y, Hao H, Liu J, Guo Y, Mu Y, Shen J, Cheng Y, Fu X, Han W. Infusion of mesenchymal stem cells ameliorates hyperglycemia in type 2 diabetic rats: identification of a novel role in improving insulin sensitivity. 2012;Jun;61(6):1616-25.

23. Sun X, Hao H, Han Q, Song X, Liu J, Dong L, Han W and Mu Y. Human umbilical cord-derived mesenchymal stem cells ameliorate insulin resistance by suppressing NLRP3 inflammasomemediated inflammation in type 2 diabetes rats. Stem Cell Res Ther. 2017;8:241.

24. Xie Z, Hao H, Tong C, Cheng Y, Liu J, Pang Y, Si Y, Guo Y, Zang L, Mu Y and Han W. Human umbilical cord-derived mesenchymal stem cells elicit macrophages into an anti-inflammatory phenotype to alleviate insulin resistance in type 2 diabetic rats. Stem Cells.2016;34:627-39.

25. Liang X, Ding Y, Zhang Y, Tse HF and Lian Q. Paracrine mechanisms of mesenchymal stem cellbased therapy: current status and perspectives. Cell Transplant.2014;23:1045-59.

26. Weil BR, Markel TA, Herrmann JL, Abarbanell AM and Meldrum DR. Mesenchymal stem cells enhance the viability and proliferation of human fetal intestinal epithelial cells following hypoxic injury via paracrine mechanisms. Surgery. 2009;146:190-197.

27. Spees JL, Lee RH and Gregory CA. Mechanisms of mesenchymal stem/stromal cell function. Stem Cell Res Ther. 2016;7:125.

28. Li, C. J.; Cheng, P.; Liang, M. K.; Chen, Y. S.; Lu, Q.; Wang, J. Y.; Xia, Z. Y.; Zhou, H. D.; Cao, X.; Xie, H.; Liao, E. Y.; Luo, X. H. MicroRNA-188 Regulates Age-Related Switch Between Osteoblast and Adipocyte Differentiation. J Clin Invest. 2015;125:1509-1522

29. Clark EA, Kalomoiris S, Nolta JA and Fierro FA. Concise Review: MicroRNA Function in Multipotent Mesenchymal Stromal Cells. Stem Cells.2014;32:1074-1082.

30. Ti D, Hao H, Fu X and Han W. Mesenchymal stem cells-derived exosomal microRNAs contribute to wound inflammation. Sci China Life Sci. 2016;59:1305-1312.

31. Ji J, Yamashita T, Budhu A, Forgues M, Jia HL, Li C, Deng C, Wauthier E, Reid LM, Ye QH, Qin LX, Yang W, Wang HY, Tang ZY, Croce CM and Wang XW. Identification of microRNA-181 by genome-wide screening as a critical player in EpCAM-positive hepatic cancer stem cells. Hepatology.2009;50:47280 . 
32. Henao-Mejia J, Williams A, Goff LA, Staron M, Licona-Limon P, Kaech SM, Nakayama M, Rinn JL and Flavell RA. The microRNA miR-181 is a critical cellular metabolic rheostat essential for NKT cell ontogenesis and lymphocyte development and homeostasis. Immunity. 2013;38:984-97.

33. Carthew, R. W.; Sontheimer, E. J. Origins and Mechanisms of MiRNAs and SiRNAs. Cell. 2009;136:642-655.

34. M. Brissova, M.J. Fowler, W.E. Nicholson, A. Chu, B. Hirshberg, D.M. Harlan, A.C. Powers, Assessment of human pancreatic islet architecture and composition by laser scanning confocal microscopy, J. Histochem. Cytochem. 2005;53 (9):1087-1097.

35. O. Cabrera, D.M. Berman, N.S. Kenyon, C. Ricordi, P.O. Berggren, A. Caicedo, The unique cytoarchitecture of human pancreatic islets has implications for islet cell function, Proc. Natl. Acad. Sci. U. S. A. 2006;103 (7):2334-2339.

36. E.W. Sutherland, C. De Duve, Origin and distribution of the hyperglycemic-glycogenolytic factor of the pancreas, J. Biol. Chem. 1948;175 (2):663-674.

37. Q. Zhang, R. Ramracheya, C. Lahmann, A. Tarasov, M. Bengtsson, O. Braha, M. Braun, M. Brereton, S. Collins, J. Galvanovskis, A. Gonzalez, L.N. Groschner, N.J. Rorsman, A. Salehi, M.E. Travers, J.N. Walker, A.L. Gloyn, F. Gribble, P.R. Johnson, F. Reimann, F.M. Ashcroft, P. Rorsman, Role of KATP channels in glucose-regulated glucagon secretion and impaired counterregulation in type 2 diabetes. Cell Metab. 2013;18 (6):871-882.

38. Hong J, Abudula R, Chen J, Jeppesen PB, Dyrskog SE, Xiao J, Colombo M and Hermansen K. The short-term effect of fatty acids on glucagon secretion is influenced by their chain length, spatial configuration, and degree of unsaturation: studies in vitro. Metabolism. 2005;54:1329-36.

39. Gao X, Song L, Shen K, Wang H, Qian M, Niu W and Qin X. Bone marrow mesenchymal stem cells promote the repair of islets from diabetic mice through paracrine actions. Mol Cell Endocrinol. 2014;388:41-50.

40. Kim MK囚 Shin $H M \otimes$ Jung $H \otimes$ et al. Comparison of pancreatic beta cells and alpha cells under hyperglycemia: Inverse coupling in pAkt-Fox01 [J]. Diabetes Res Clin Pract.2017;131: 1-11.

41. Gromada J, Franklin I, Wollheim CB. Alpha-cells of the endocrine pancreas: 35 years of research but the enigma remains. Endocr Rev. 2007;28:84-116.

42. Wang XL, Zhang L, Youker K, Zhang MX, Wang J, LeMaire SA, Coselli JS and Shen YH. Free Fatty Acids Inhibit Insulin Signaling-Stimulated Endothelial Nitric Oxide Synthase Activation Through Upregulating PTEN or Inhibiting Akt Kinase. Diabetes. 2006;55:2301-2310.

43. Wang L, Liu Y, Yan Lu S, et al. Deletion of Pten in pancreatic b-cells protects against deficient b-cell mass and function in mouse models of type 2 diabetes. Diabetes. 2010;59:3117-3126.

44. Ebert PJ, Jiang S, Xie J, Li QJ and Davis MM. An endogenous positively selecting peptide enhances mature $T$ cell responses and becomes an autoantigen in the absence of microRNA miR-181a. Nat Immunol. 2009;10:1162-9.

45. Carreras-Badosa G, Bonmati A, Ortega FJ, Mercader JM, Guindo-Martinez M, Torrents D, Prats-Puig A, Martinez-Calcerrada JM, de Zegher F, Ibanez L, Fernandez-Real JM, Lopez-Bermejo A and Bassols J. 
Dysregulation of Placental miRNA in Maternal Obesity Is Associated With Pre- and Postnatal Growth. J Clin Endocrinol Metab. 2017;102:2584-2594.

46. Kornfeld JW, Baitzel C, Konner AC, Nicholls HT, Vogt MC, Herrmanns K, Scheja L, Haumaitre C, Wolf AM, Knippschild U, Seibler J, Cereghini S, Heeren J, Stoffel M and Bruning JC. Obesity-induced overexpression of miR-802 impairs glucose metabolism through silencing of Hnf1b. Nature. 2013;494:111-5.

\section{Figures}
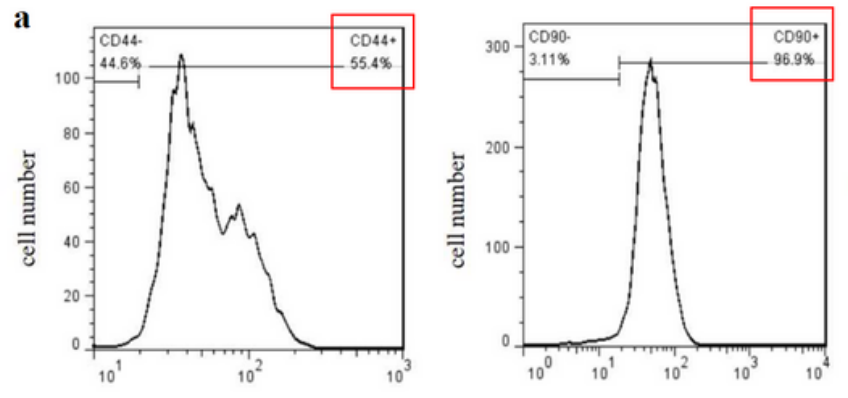

b
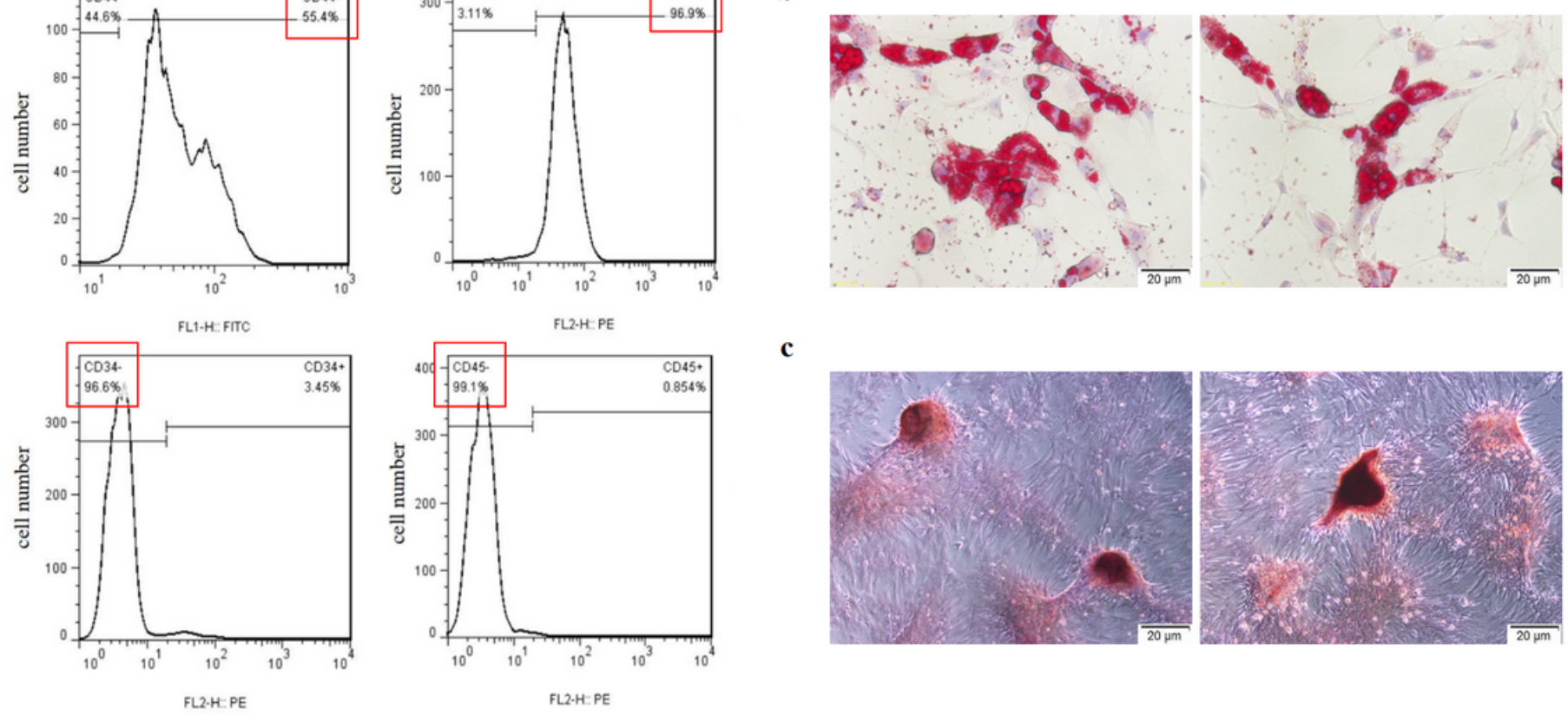

c

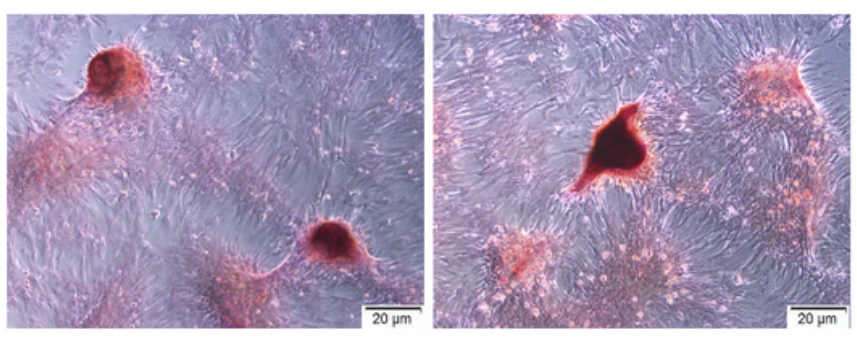

\section{Figure 1}

Identification of BM-MSCs. a. BM-MSCs were positive for stem cell markers CD90 and CD44 and negative for hematopoietic markers CD34 and CD45, which were assessed by flow cytometry analysis. b. Adipogenic differentiation was identified by intracellular lipid droplets stained in red by Oil Red O. c. Osteogenic differentiation of MSCs was identified by the formation of calcium nodes stained in red by Alizarin Red. 

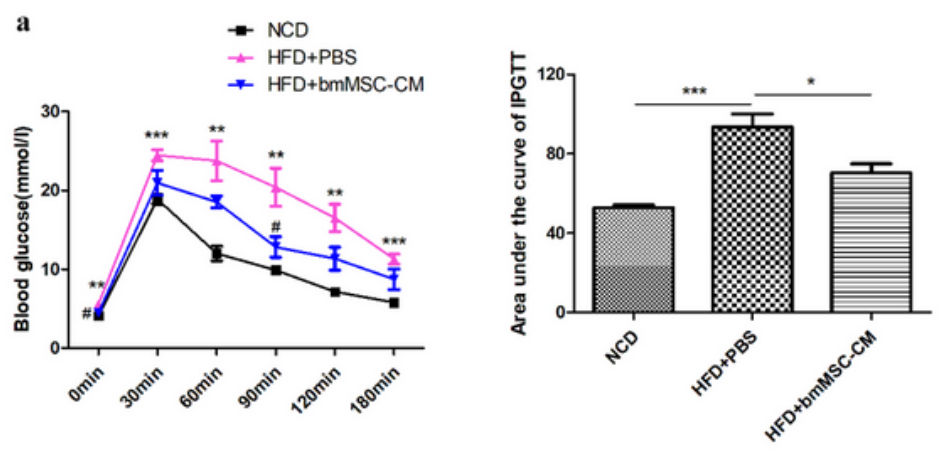

b

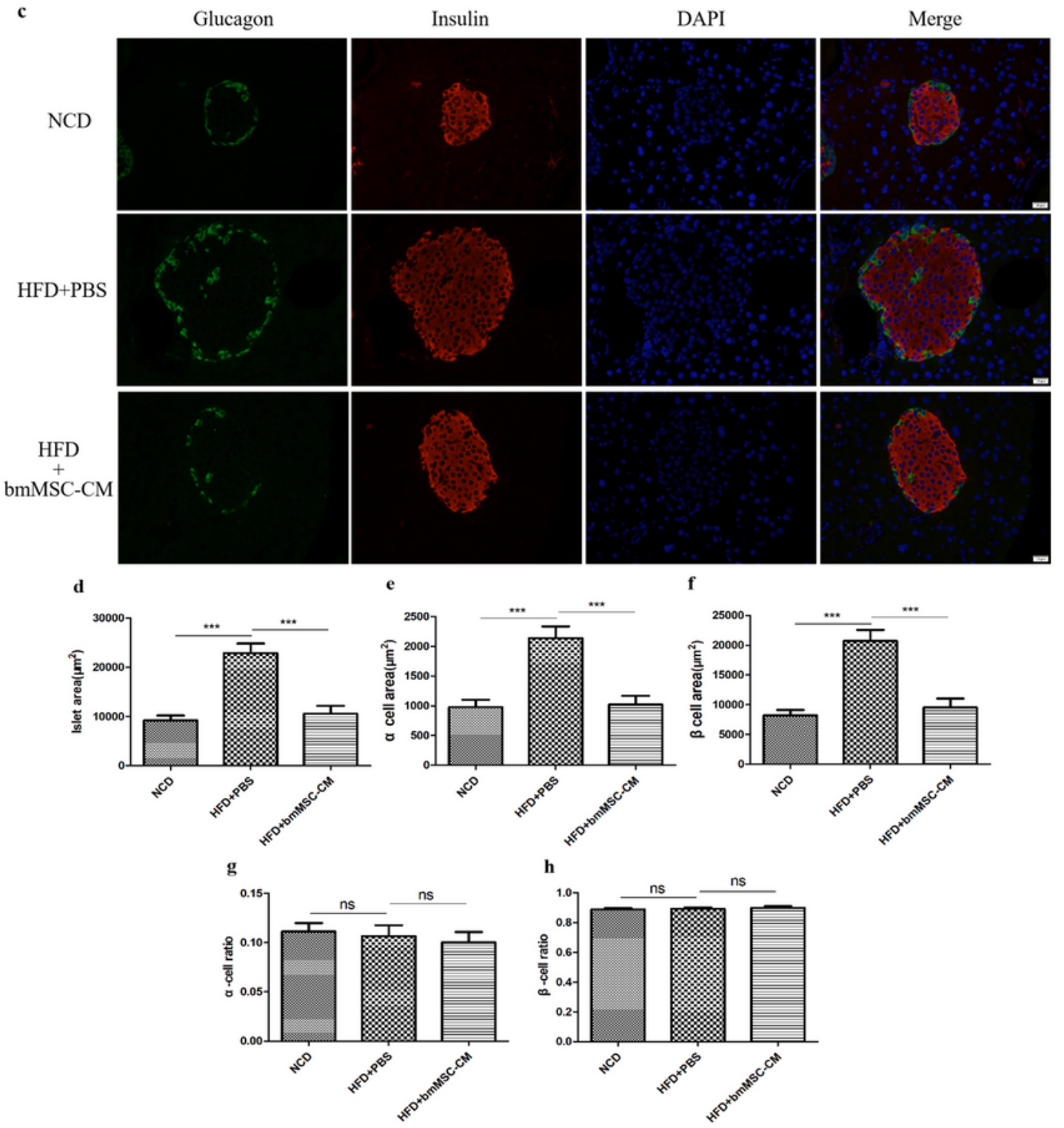

Figure 2

MSC-CM infusion ameliorated HFD-induced hyperglycemia and hyperglucagonemia in mice. a. MSC-CM infusion significantly reduces fasting glucose levels and improves glucose tolerance during IPGTT. The AUC supports the above conclusion. b. MSC-CM infusion mitigates HFD-induced hyperglucagonemia. C and d. MSC-CM infusion ameliorates HFD-induced hypertrophy of islets and decreases islet area. e and f. MSC-CM infusion decreases islet $\alpha-$ and $\beta$-cell area. $g$ and $h$. No change in the $\alpha$ - and $\beta$-cell ratio is 
observed (compared with the NCD group: ${ }^{* \star} p<0.05 ;{ }^{* \star} p<0.01 ;{ }^{* \star} p<0.001$; compared with the HFD+PBS group: \#p<0.05. ns: not significant).

a

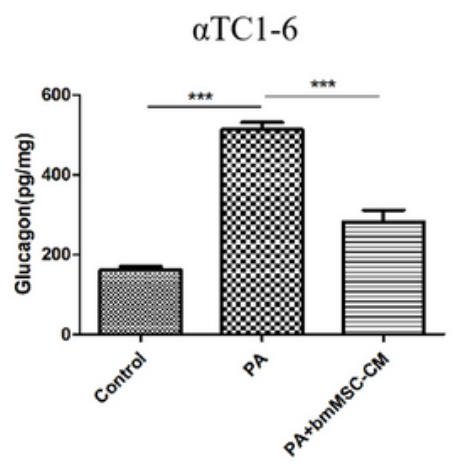

c

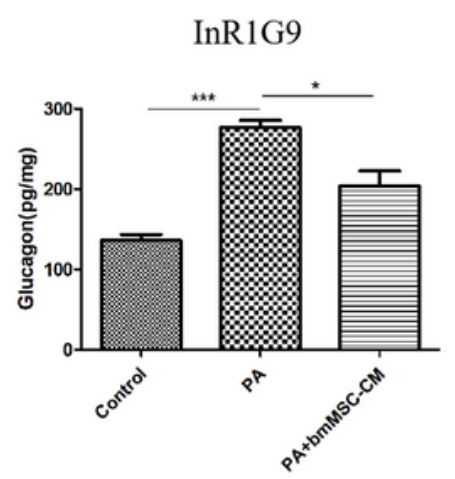

e

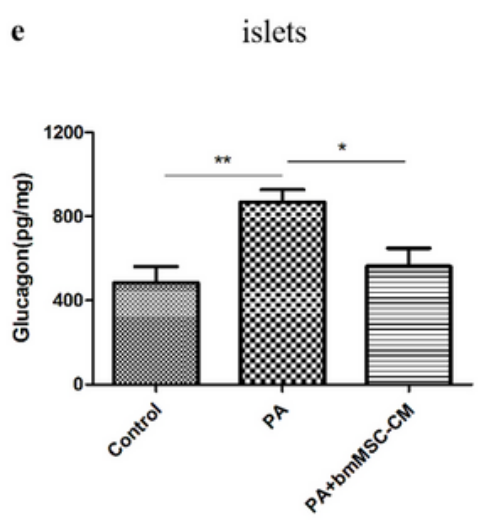

b
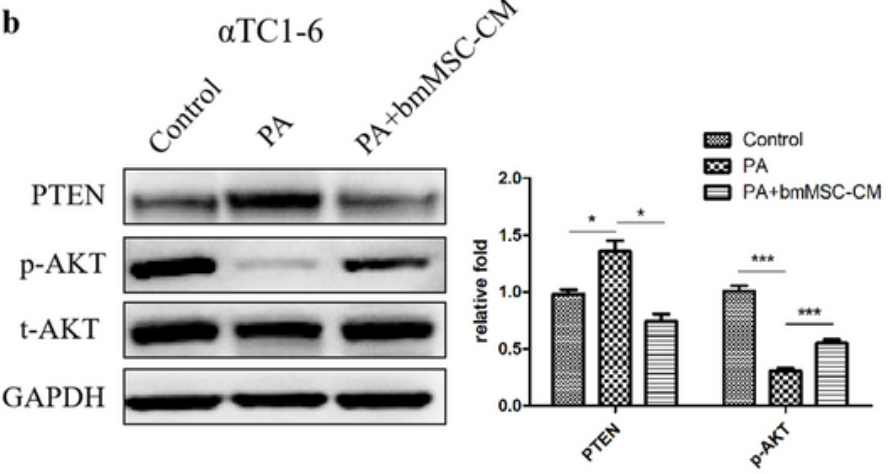

d
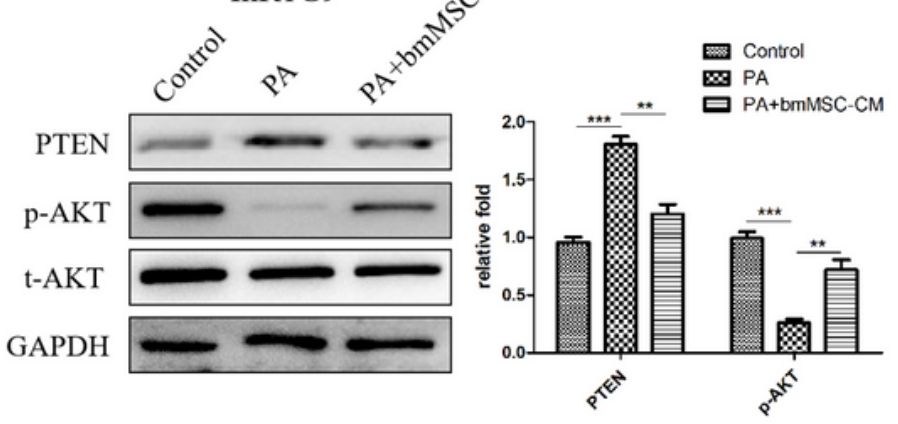

f
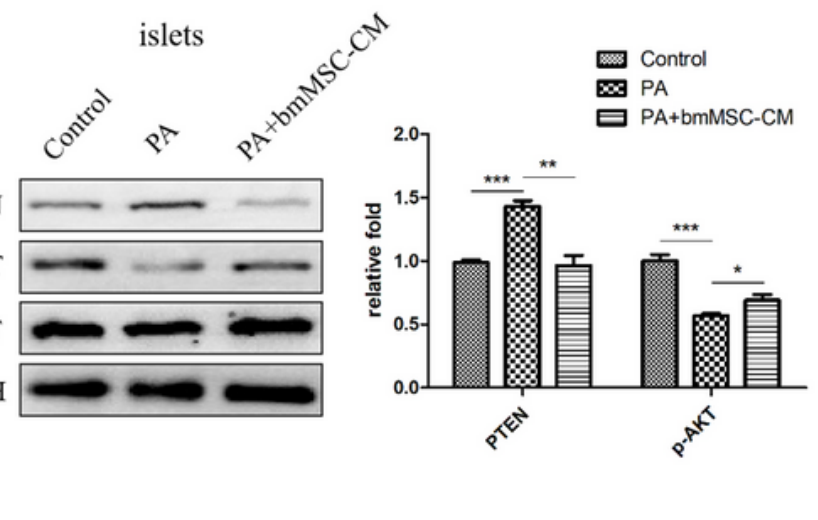

Figure 3

MSC-CM regulated palmitate-induced hypersecretion of glucagon and PTEN/AKT signaling in a-cells and islets. a, c, e. MSC-CM markedly decreases PA-induced glucagon secretion in aTC1-6 cells, InR1G9 cells and isolated islets. b, d, f. MSC-CM decreases PA-induced intracellular PTEN expression and rescues 
phosphorylation of AKT (Ser473) in both a-cells and isolated islets. Quantification of bands was performed using ImageJ software ( $\left.{ }^{*} p<0.05 ;{ }^{* \star} p<0.01 ;{ }^{* \star *} p<0.001\right)$. Fig. 4 PTEN deletion suppresses PAinduced glucagon secretion of a-cells. a. siRNA PTEN transfection efficiently reduces PTEN protein expression and increases p-Akt signaling. b. PA-induced glucagon secretion is attenuated after PTEN knockdown. Quantification of bands was performed using ImageJ software $\left({ }^{\star} p<0.05 ;{ }^{* \star} p<0.01\right.$; $\star \star \star p<0.001)$.
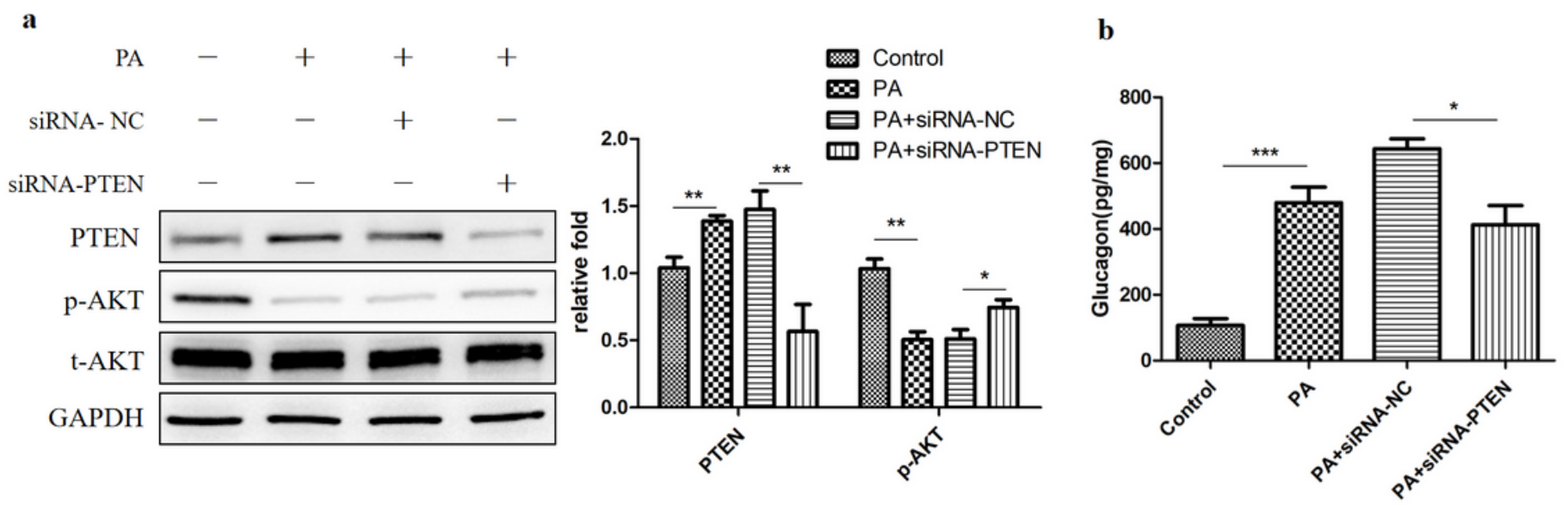

\section{Figure 4}

PTEN deletion suppresses PA-induced glucagon secretion of a-cells. a. siRNA PTEN transfection efficiently reduces PTEN protein expression and increases p-Akt signaling. b. PA-induced glucagon secretion is attenuated after PTEN knockdown. Quantification of bands was performed using ImageJ software $\left({ }^{*} \mathrm{p}<0.05 ;{ }^{* \star} \mathrm{p}<0.01 ;{ }^{* \star *} \mathrm{p}<0.001\right)$. 

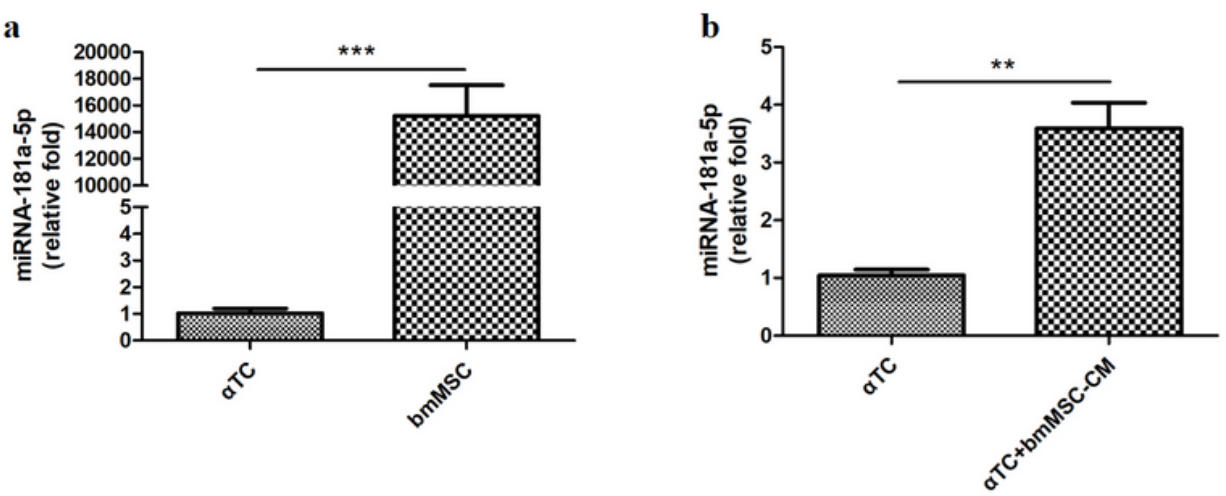

c 300 319 PTEN WT 3'UTR $\quad$ 5'-UGAUUUUGAAUGUUUCAGUG-3' rno-miR-181a-5p 3'-GUCGCAACUUACAAACUCUCUUA-5' PTEN mutant 3'UTR 5'-UGAUUUGUCCGUGGUCAGUG-3'

음 PTEN WT 3'UTR+miR-181a-5p NC $\$$ PTEN WT 3'UTR+miR-181a-5p mimics 曰 PTEN Mutant 3'UTR+miR-181a-5p NC 血 PTEN Mutant 3'UTR+miR-181a-5p mimics

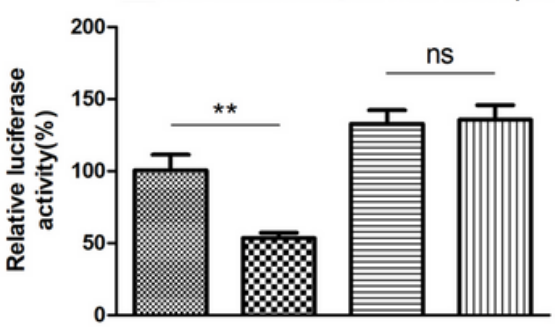

\section{Figure 5}

Verification of miR-181a-5p and its target gene. a. miR-181a-5p levels in BM-MSCs are significantly higher than aTC1-6 cells, which was confirmed by RT-qPCR. b. Upregulated expression of miR-181a-5p in aTC1-6 cells after treatment with MSC-CM. c. Schematic of the sequence that miR-181a-5p targets in the WT or mutated 3' UTR of PTEN mRNA. d. The luciferase activity of PTEN WT or mutated 3' UTR reporter plasmids in aTC1-6 cells co-transfected with miR-181a-5p mimics or miR-NC $\left(\star \star p<0.01 ;{ }^{* \star} p<0.001 ; n s\right.$, not significant). 
a

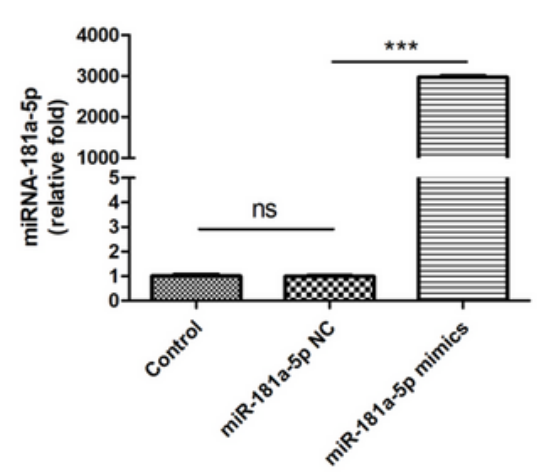

c

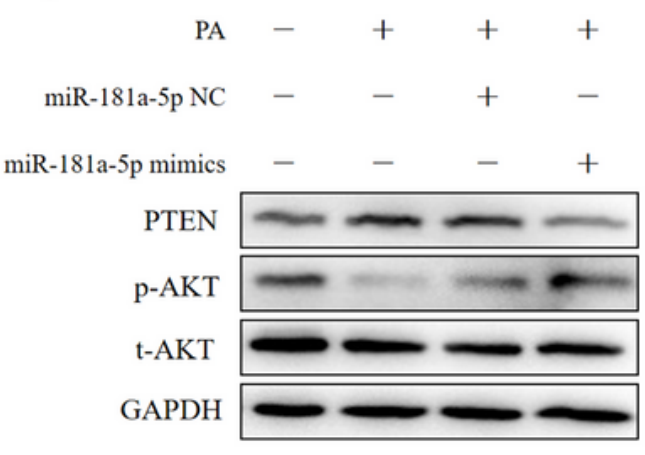

d

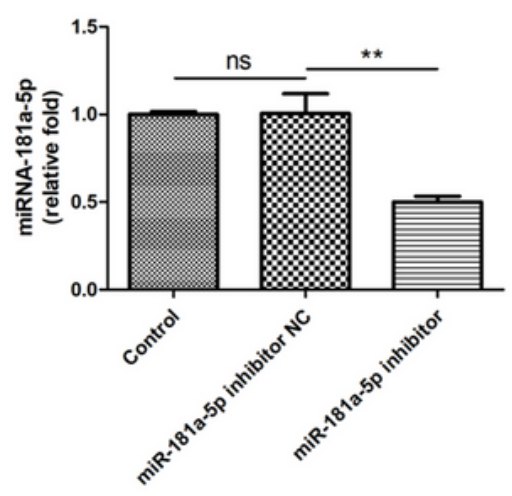

miR-181a-5p inhibitor NC $-\quad+\quad-\quad+$

miR-181a-5p inhibitor $\quad-\quad-\quad+\quad-$

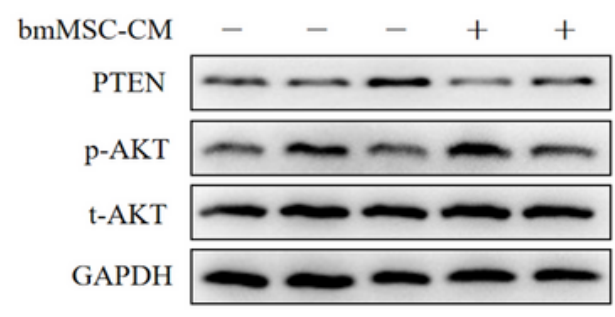

b
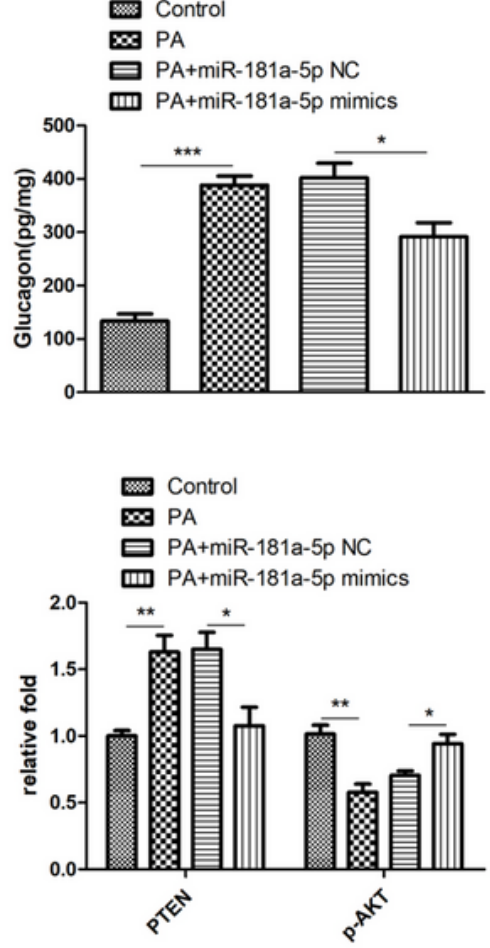

e $\quad$ Control

品 miR-181a-5p inhibitor

而 miR-181a-5p NC+bmMSC-CM

miR-181a-5p inhibitor+bmMSC-CM

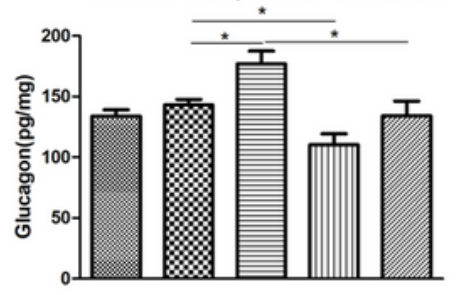

Control

$\infty$ miR-181a-5p NC

DiR-181a-5p inhibitor

而 miR-181a-5p NC+bmMSC-CM

miR-181a-5p inhibitor+bmMSC-CM

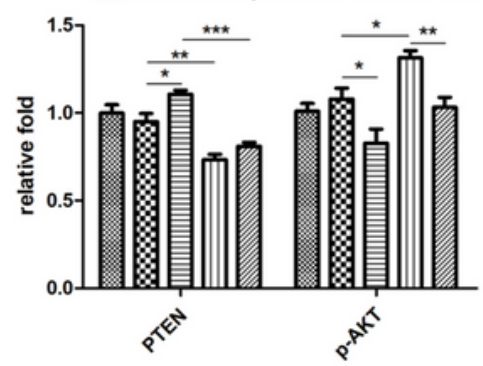

\section{Figure 6}

MSC-secreted miR-181a-5p is involved in regulating glucagon secretion and PTEN/AKT signaling in acells. a and d. The expression of miR-181a-5p is significantly increased by mimics (a) and reduced by inhibitor (d) as detected by qPCR analysis. b. A decrease in PA-induced glucagon secretion was observed after transfection with miR-181a-5p mimics. c. Reduction in PTEN expression and recovery of p-AKT with miR-181a-5p mimics transfection. e and f. miR-181a-5p inhibitor transfection enhances glucagon 
secretion (e), upregulated the expression of PTEN and decreased p-AKT signaling (f). Additionally, MSC$\mathrm{CM}$ partially rescued this process. Quantification of bands was performed using Image $J$ software ( ${ }^{\star} p<0.05 ;{ }^{* \star} p<0.01 ;{ }^{* \star \star} p<0.001$; ns, not significant). 